\title{
Memories of Mary Ellen Rudin
}

\section{Georgia Benkart, Mirna Džamonja, and Judith Roitman, Coordinating Editors}

\begin{abstract}
Steven G. Krantz, editor of the Notices, invited the editors of this article to prepare a collective remembrance celebrating Mary Ellen Rudin's life and work. In doing so, we asked several of Mary Ellen's colleagues, collaborators, and students to each contribute a short piece. The choice of contributors was not an easy one, since Mary Ellen had a very rich mathematical and social life, to which this article can only attest. Space limitations meant that we could not accommodate all who would have liked to pay tribute to her, but we hope that they will find themselves, at least to some extent, represented by the reminiscences appearing here.

This article is far from being the only initiative to celebrate Mary Ellen Rudin, and we are particularly happy to mention two additional ones: the Mary Ellen Rudin Young Researcher Award Fund established by Elsevier and an upcoming special issue of Topology and Its Applications edited by Gary Gruenhage, Jan van Mill, and Peter Nyikos.
\end{abstract}

\section{Georgia Benkart}

Mary Ellen Estill Rudin, Grace Chisholm Young Professor Emerita of Mathematics at the University of Wisconsin-Madison and preeminent set-theoretic topologist, died at her home in Madison, Wisconsin, on March 18, 2013. Mary Ellen was born December 7, 1924, in Hillsboro, Texas, south of Dallas-Fort Worth, a small town whose roster of notable natives also includes Madge Bellamy, a film actress of the 1920s and 1930s best known for the horror movie classic White Zombie.

When she was six, Mary Ellen's family moved to the even smaller town of Leakey (LAY-key) situated in the Texas hill country in a canyon carved out by the Frio and Nueces Rivers. Her mother, Irene Shook Estill, had taught high school English. Her father, Joe Jefferson Estill, was a civil engineer with

Georgia Benkart is professor emerita of mathematics at the University of Wisconsin-Madison. Her email address is benkart@math.wisc.edu.

Mirna Džamonja is professor of mathematics at the University of East Anglia, Norwich, UK. Her email address is M.Dzamonja@uea.ac.uk.

Judith Roitman is professor emerita of mathematics at the University of Kansas. Her email address is j roi tman@ku . edu. DOI: http://dx.doi.org/10.1090/noti1254

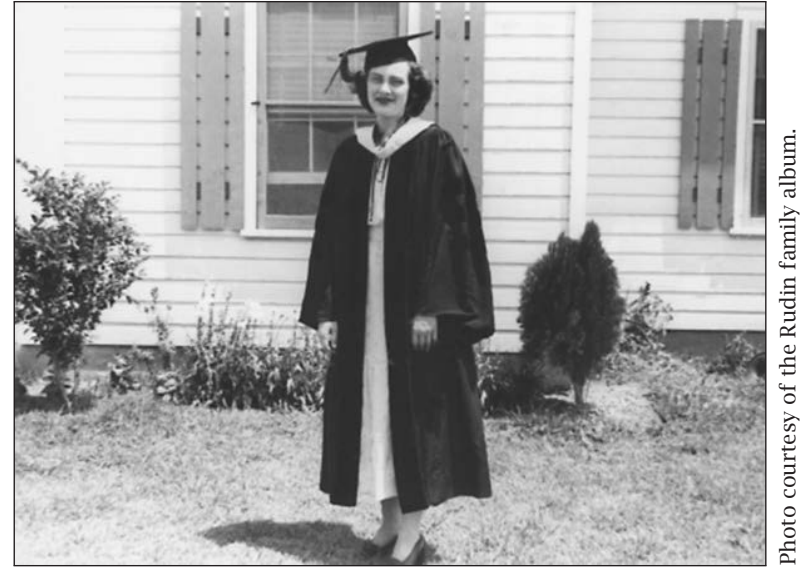

Mary Ellen's graduation from the University of Texas, 1949.

the Texas Highway Department, and the family had moved around as his projects dictated until, soon after their arrival at Leakey, the Depression hit. As there was no money to build new roads, the family stayed there throughout Mary Ellen's school years while her father did surveying work. Her brother, Joe Jefferson Estill Jr., was ten years younger; the two siblings always got along famously despite 


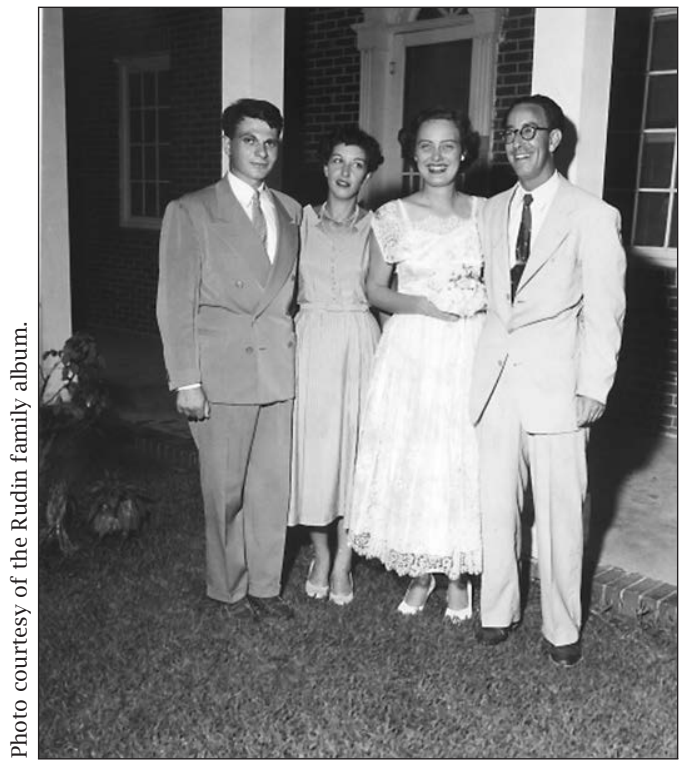

Walter's sister, Vera Usdin, and her husband, Earl Usdin, at the wedding of Mary Ellen and Walter in 1953. their age difference. In those days, reaching Leakey from the outside world required traveling fifty miles up a one-lane dirt road and fording the Frio River seven times. Children walked to school or rode there on horseback.

In 1941 Mary Ellen was one of five graduates in her high school class. That fall she headed off to Austin to enroll at the University of Texas and was directed to the table with the shortest line of prospective students, where Robert L. Moore sat registering students for mathematics courses. Impressed with her correct usage of "if/then" and "and/or," Moore signed Mary Ellen up for a trigonometry course. She was surprised to discover the next day that he was the professor for the class. Every single semester during her entire eight years at the University of Texas, from day one until she graduated with her doctoral degree in 1949, she attended a course taught by Moore [Ke].

Moore's method of teaching, which eschewed formal lectures, instilled in Mary Ellen a lifelong deep confidence in solving problems and conjectures, though she never used the method in her own teaching. As she later put it in an interview with Albers and Reid [AR], at the end of her freshman calculus course, "I'm not sure I knew the derivative of $\sin x$ was $\cos x$, but I could prove all sorts of theorems about continuity and differentiability and so on!" Mary Ellen often bemoaned the fact that she knew so little mathematics and felt cheated that she had not been exposed to basic subjects such as algebra and analysis.

At Texas she was a member of a terrific cohort of Moore graduate students, including Richard Anderson, Ed Burgess, R. H. Bing, and Edwin Moise, that went on to shape general topology and leave its mark on the mathematical community. In her doctoral thesis, Mary Ellen constructed a counterexample to a well-known conjecture using a technique now called "building a Pixley-Roy space" after the two mathematicians who later gave a more simplified description of it. At the time she wrote her thesis, she had never read a single mathematics paper. She maintained an aversion to reading research papers throughout her career, loved talking about mathematics and sharing her bounty of ideas with anyone who would listen, and was an avid colloquium goer (but always with pencil and paper just in case her interest in the subject waned).

After Mary Ellen earned her PhD in 1949, Moore referred her to Duke University, which then had a women's college under pressure to hire a female mathematician. At Duke she met Walter Rudin. Walter had arrived there in 1945 from England, where he had spent the war years in the Royal Navy after fleeing Austria. Having convinced a dean that he should be admitted as a junior even though he had never finished high school, four years later, in 1949, Walter completed his PhD. He left Duke in 1950 for a two-year C. L. E. Moore Instructorship at MIT and following that for the University of Rochester, but Mary Ellen and Walter continued to see each other at the winter and summer Joint Mathematics Meetings. In August 1953 they were married at the home of her parents in Houston. While at Duke, Mary Ellen proved a conjecture of Raymond Wilder, an early Moore student, and Wilder applied for an NSF grant to enable her to visit him at the University of Michigan. When she wired Wilder that she was getting married and going to the University of Rochester, somehow he managed for the grant to be transferred from Michigan to Rochester. The University of Rochester came up with a part-time position for her on short notice, and she continued her research. Daughter Catherine arrived in July 1954, and daughter Eleanor in December 1955, so part-time teaching suited the newly expanded family.

The Rudins were on leave from Rochester visiting Yale for the academic year 1958-59 when R. H. Bing phoned Walter to invite him to give a summer course at the University of Wisconsin. Walter declined because he already had Sloan Fellowship funding for the summer but heard himself asking, "But how about a real job?" [RW]. Bing, who was mathematics department chair at the time, arranged an interview a few weeks later. In 1959 the Rudin family moved to Madison and purchased a recently built home designed by Frank Lloyd Wright that consisted of basically one large room with 14-foot ceilings and a huge number of windows (rumored to be 137). Sons Robert (Bobby)* and Charles (Charlie) were born in Madison in 1961 and 1964. Although Walter retreated to the quiet of his study to do mathematics, Mary Ellen described

\footnotetext{
*Son Robert Rudin died in Madison, Wisconsin, October 13,
} 2014. 
her own mode of work as "I lie on the sofa in the living room with my pencil and paper and think and draw little pictures and try this thing and that thing....It's a very easy house to work in. It has a living room two stories high, and everything else opens onto that....I have never minded doing mathematics lying on the sofa in the middle of the living room with the children climbing all over me" [AR].

Madison turned out to be exactly the right kind of place for them-the right kind of city and the right kind of mathematics department [RW]. Mary Ellen continued as a part-time lecturer who supervised graduate students and engaged in essentially full-time research until 1971, when, in Walter's words [RW], "The anti-nepotism rules, which were actually never a law, had fallen into disrepute," and she was promoted from part-time lecturer to full professor. Mary Ellen was somewhat dubious about the professorship because of the teaching and committee work it entailed, but Walter felt it was best, especially for the children, in case something should happen to him. One of my earliest recollections of Mary Ellen is sharing an elevator with her in the mid-1970s, where she showed me a printout with the small retirement sum she had accumulated since coming to Wisconsin, a reality check the ever-expanding ranks of adjuncts and part-timers teaching mathematics today are also bound to face.

Mary Ellen was known for her extraordinary ability to construct ingenious counterexamples to outstanding conjectures, many quite complicated. She was the first to construct a Dowker space, thereby disproving a long-standing conjecture of Hugh Dowker that such spaces couldn't possibly exist. Years before this noteworthy accomplishment, in 1963 her solution to one of the Dutch Prize Problems had been recognized by the Nieuw Archief voor Wiskunde (the Mathematical Society of the Netherlands). In later years she was named a Fellow of the American Academy of Arts and Sciences and of the American Mathematical Society, became a member of the Hungarian Academy of Sciences, and received four honorary Doctor of Science degrees. She gave an invited lecture at the International Congress of Mathematicians in Vancouver in 1974 and the Noether Lecture of the Association for Women in Mathematics at the Joint Mathematics Meetings in 1984. In 1990 she was awarded the R. H. Bing Prize for significant overall contributions to mathematics. She served as vice president of the AMS 1980-81; as MAA governor 1973-75; and on a vast number of AMS, MAA, and national committees, including the editorial boards of the Notices and of Topology and Its Applications. Perhaps ironically, she chaired the AMS Committee on Academic Freedom, Tenure, and Employment

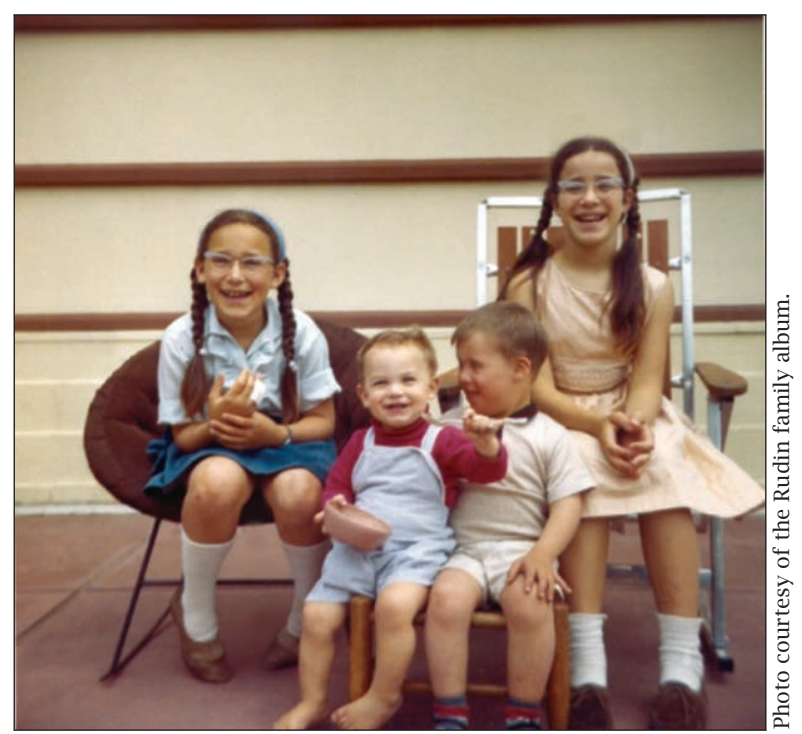

Eleanor, Charlie, Bobby, and Catherine Rudin.

Security. In her honor, Elsevier established the Mary Ellen Rudin Young Researcher Award Fund to celebrate her achievements and to recognize her legacy in encouraging talented young researchers in topology. This award was formally announced at the 47th Spring Topology Meeting a week after her death, though she had given her approval of it earlier. The inaugural prize was awarded in September 2013 to Logan C. Hoehn of Nipissing University, Canada, a mathematical descendant of Mary Ellen.

Mary Ellen never stopped thinking about mathematics and working on problems. She was a mainstay of the Southern Wisconsin Logic Colloquium and couldn't wait to tell me about her "fabulous weekend" when the colloquium hosted the Association for Symbolic Logic meeting in April 2012. The talks were fantastic, she reported; she met lots of old friends and, of course, participated in all the social gatherings.

The Rudins welcomed mathematicians, Wright aficionados, and students from all over the world to their unique home. The door was always openliterally; it was never locked. As Mary Ellen once said to me, "People just open the door and say 'Hello, we're here.'” To which daughter Catherine quickly added, "And most of the time we know them." The Rudins entertained often and hosted everyone with a gracious, relaxed style. I remember a Thanksgiving when, with her customary cheerfulness, Mary Ellen announced to the gathering that dinner would be delayed, as the turkey, which was being cooked outside because the oven wasn't working, had been on fire.

Mary Ellen was larger than life, and her reputation for rescues almost as legendary as her 


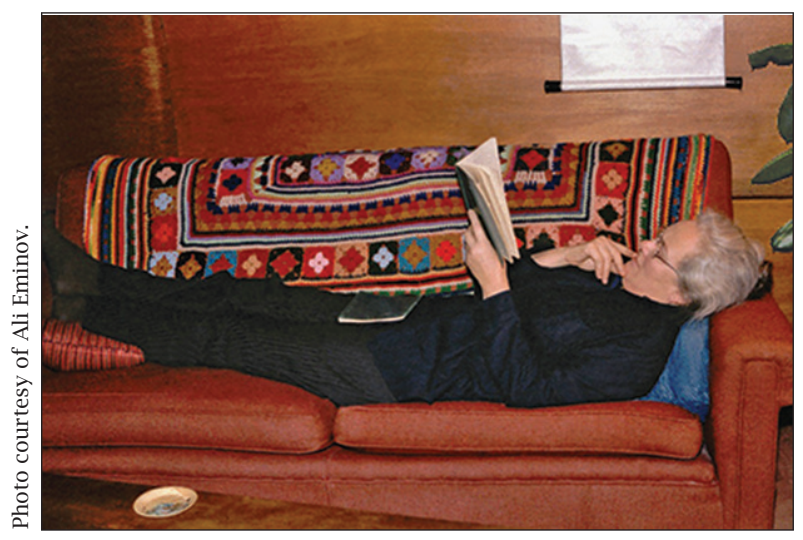

Mary Ellen on the sofa.

counterexamples. On more than one occasion she saved a child from the deep end of a pool or from crashing ocean waves. At an AMS summer mathematics institute in Colorado, a horse suddenly took off at a gallop, with the young rider who had slipped from the saddle dangling off to one side. Mary Ellen charged after them on horseback, corralled the runaway horse, and righted the girl, the daughter of the Rudins' longtime friend Yale mathematician Shizuo Kakutani, Michiko Kakutani, now a Pulitzer Prize-winning literary critic for the New York Times.

For well over twenty years, except for the five years that Linda Rothschild was in the department, Mary Ellen and I were the only women mathematics faculty members at Wisconsin. Mary Ellen's passion for mathematics was contagious, her support and encouragement to all extraordinary. She meant so much to so many; it was inspiring to be a part of her remarkable life. She was so accepting, so warm and welcoming, so genuine, so fiercely independent. She would never think to tell any of us that she had been taken to the hospital by ambulance in the middle of the night, except when it occurred to her she had left the house in just her nightgown with no shoes or money and no way to get back home. After Walter's death, several of us would get together regularly for dinner, and she would want to drive. "We'll pick you up," I'd tell her. "Oh, ok," she would reply. "I'll be ready". And she always was.

\section{István Juhász}

Many of us who had close personal and professional contact with Mary Ellen Rudin received with deep sorrow the news that she died on March 18 in the eighty-ninth year of her life. In this age of

István Juhász is professor emeritus at Alfréd Rényi Institute of Mathematics, Hungarian Academy of Sciences, Budapest, Hungary. His email address is juhasz@renyi . hu. the Wikipedia and numerous other easily available public sources of information, I don't think it's necessary for me to give a detailed account of her great scientific achievements, most of which were done in the field of general and set-theoretic topology. Instead, I take this opportunity to recall a few personal memories about her.

The first of these concerns a paper of hers in which she presented an example of a firstcountable and CCC regular space that is not separable and which, as a student, I presented in our topology seminar. I still remember how proud it made me that I could understand, and make more or less clear to the audience, her very complicated construction. I only much later found out the explanation of the rather nonstandard notation and terminology she used (and which made her technically very complicated ingenious construction even harder to understand): She was brought up in the (in)famous Moore school in Texas, where students were forbidden to study math books; they had to discover everything on their own. I recall a story I heard from Paul Erdős, a good friend of the Rudins, that illustrates this. On one of his visits with them he was surprised to find out that she did not know what a Hilbert space was. This was sometime in the 1950s, and, of course, she later became much more familiar with and well versed in what was going on in her field.

Our first meeting in person took place at the IMU Congress in Nice in the summer of 1970. Together with my friend and collaborator András Hajnal we were eager to meet her, and this happened right after she arrived in Nice. Her first sentence to us was "I just proved that there is a Dowker space;" i.e., a normal space whose product with the unit interval is not normal. To appreciate the weight of this sentence, one should know that this meant she solved the most important open problem of general topology of the 1960s.

The next year I made a short, basically personal, visit to North America, and she invited me to Madison to give a talk there. That was the first of many occasions when she, as a caring host, treated me so well, both mathematically and socially. Of course, she invited me to their beautiful house designed by Frank Lloyd Wright, cooked a great meal for me, and showed me around town. I was glad to be able to return some of her favors in the summer of 1973 when she came to Hungary, together with her two then-teenage daughters, for a topology conference.

She was the architect of arranging a visiting position for me at the University of WisconsinMadison for the academic year 1974-75. This was not a trivial thing in those Cold War times. One result of this visit was our joint paper [JKR] with 
Ken Kunen, which is a very frequently cited paper in the field of set-theoretic topology. This visit was followed by many more visits to Madison, most of them organized by her. But I'd like to mention another trip of mine to the US in which she played a substantial role.

This took place in 1983 when my friend Endre Szemerédi had been diagnosed with a serious case of cancer while on a visit in the US. Of course, after having found this out, I turned to Mary Ellen to ask if she could arrange a visit to Madison for me so that I could see my ailing friend. It turned out that this was not possible because of some financial problems at UW Madison. Still, she managed to convince the head of another math department in the US-as I later found out, not without some arm twisting - to invite me, thus making it possible for me to visit my friend right after he had a very serious operation. This story has a very happy ending: My friend has completely recovered, and, as is well known, in 2012 he was awarded the Abel Prize.

I was fortunate to be present at Mary Ellen's retirement meeting in Madison in 1991, where I could witness her efforts trying to help Boris Shapirovskii, another great mathematician fighting cancer, unfortunately in his case with no success.

I was very happy and proud when in 1995, mainly thanks to the strong recommendation of András Hajnal, she was elected to be an honorary member of the Hungarian Academy of Sciences. Moreover, the next year she and her husband, Walter, after visiting Prague and Vienna, Walter's hometown, managed to come to Budapest so that she could deliver her acceptance address at the academy. A high point of this trip was that my family had the good fortune to host a meal in our home for the Rudins, the Shelahs, the Hajnals, and Paul Erdős, who, sadly, died just a few weeks later.

I last saw Mary Ellen in person in 2009 at the Kunen Fest, Ken Kunen's retirement celebration. Although quite fragile physically, she was as cheerful as ever. And the last email I got from her was sent in November of 2010, congratulating us on the occasion of the birth of our grandson.

\section{William Fleissner}

Mary Ellen Rudin was an inspiration to me and other graduate students. Intellectually, she was enthusiastic about set-theoretic topology. Emotionally, she was warm and kind not only to mathematicians but also to their spouses.

I remember seminars on the ninth floor of Van Vleck Hall, with large windows overlooking

William Fleissner is professor emeritus of mathematics at the University of Kansas. His email address is fleissn@ku. edu.

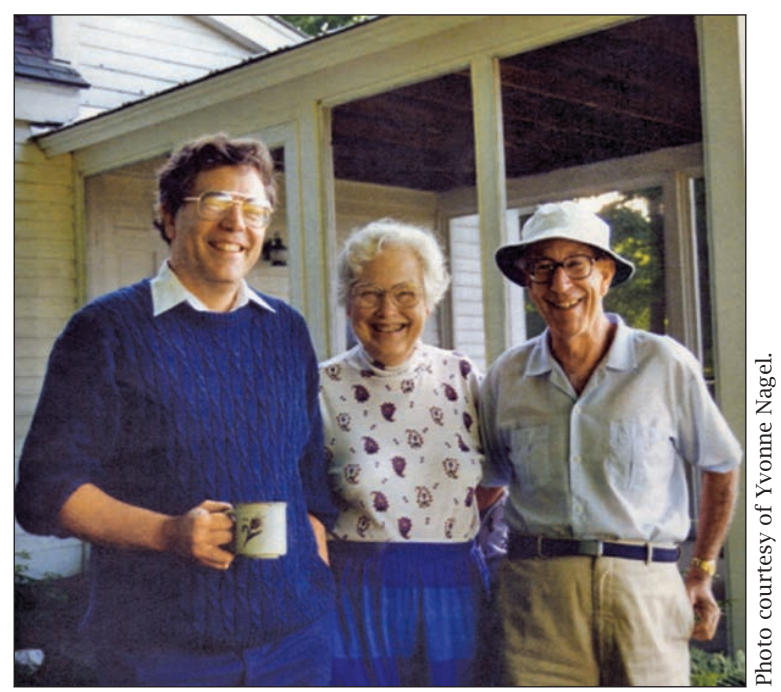

Alex Nagel, Mary Ellen and Walter.

Lake Mendota and the city of Madison. Once she presented the Reed-Zenor proof that locally compact, locally connected normal Moore spaces are metrizable. She drew a Cantor tree, put a unit interval at the top of each branch, sketched a red circle about the 0's and a blue circle about the 1's. It was not a proof of the theorem. It was more an explanation why a counterexample cannot be constructed from Martin's Axiom. Even that was not rigorously proved. But she conveyed the ideas with great enthusiasm. In the audience, I thought, "I want to do mathematics like that!"

There were memorable evenings at their Frank Lloyd Wright-designed house on Marinette Trail. (Occasionally, tourists would look in the windows, and Walter would stick out his tongue.) There would be food and drink in the kitchen, and a circle of chairs in the living room, which was large in width and length and two stories high. The winters in Wisconsin can be bitterly cold, but then there would be a fire in the fireplace, making the gathering warm and cheery. The conversation was varied, and everyone was welcome to talk, not just the distinguished professors. The research group at Wisconsin felt like a big family.

\section{Judith Roitman}

She claimed that she did most of her work on what she called her theorem-proving couch, and other mathematicians joked about how they wished they had couches which could prove theorems, but it wasn't just theorems. She created examplessome easy, some difficult, and some which were breathtaking, almost audacious. Her theorems and examples cut a wide swath through a world that, when she began, was known as point-set topology and which relatively soon, in large part because 


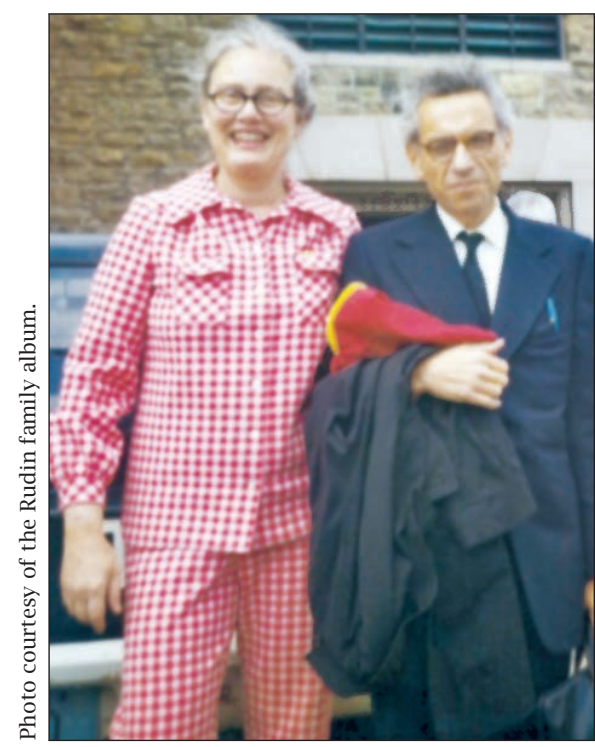

Mary Ellen and Paul Erdős when he received an Honorary Doctor of Science degree from the University of Wisconsin in 1973 (her Erdős number is 1).

of the kind of work she did and the kind of influence she had on others, came to be known as set-theoretic topology.

The difficult, breathtaking, audacious examples came about because, to her, complexity, intrinsic complexity, came easily. Her work is, as Steve Watson [W] wrote in the 1993 Festschrift to honor her seventieth birthday, "just hard mathematics, that's all." To pick one example: She looked at an arbitrary Suslin tree $T$ and saw not just an $L$-space out of its branches, which everyone else saw, but an $S$-space constructed out of triples in $\omega \times \omega_{1} \times T$ whose neighborhoods came from not quite subtrees related to each other in an intertwined fashion so complex that, working through it, you think, "This can't possibly work." But it does [R72a]. Yet, as is evident in the brief description of this construction in her 1975 CBMS notes [R75], she did not see her $S$-space from a Suslin tree as particularly difficult. That is what I mean by breathtaking and audacious.

Aside from her results, there was her influence. There were three aspects to this: she brought people together, she encouraged anyone who was interested, and she knew where we should be looking: in particular, her 1975 Lectures on Set Theoretic Topology [R75], from the 1974 CBMS Regional Conference in Laramie, set the agenda for decades.

Her hospitality and warm presence were both legendary and a major part of her influence. Consider how I met her. I was a graduate student at Berkeley wanting to use set theory to do topology and thus wanting to spend time in Madison. Arrangements were made. As soon as I arrived, I called Mary Ellen, per her instructions. She apologized that she could not help me get settled right away because her father had just died and she had to leave town for his funeral. Would I be okay for the next couple of days until she could get back? I am still astonished at the kindness of this gesture from a major mathematician to a very new graduate student barely past quals.

There were so many gestures like that to so many people, helping to form and nurture a community, a floating crew which would meet up in Prague, Warsaw, the Winter School, the Spring Topology Conference....It was an extraordinarily fertile time. I remember one summer in the mid-1970s when a number of us converged simultaneously on Madison for an impromptu summer-long seminar that met several times a week. Every meeting began with Mary Ellen asking, "Who proved a theorem last night?" and at every meeting several hands were raised.

Along with her warmth was an immense good cheer born of deep integrity and an unblinking sense of reality. When my first baby died of meningitis, Mary Ellen wrote the words that I turned to again and again, telling me how it was for her when her son Bobby was born with Down syndrome, and the doctors laid out a hopeless future for him (the hopelessness of which-Mary Ellen and Walter being who they were, refusing to pay attention to what was then accepted wisdomdid not come to pass): "Your life will never be quite the same again." There was tremendous comfort in those words.

Much about Mary Ellen was symbolized to me by the kitchen radio, an AM radio, already very old when I first noticed it. I asked Mary Ellen years later why they didn't have a newer, better model, and she said, "Because it still works." A few years ago I noticed that the radio was gone. What happened to it? "It stopped working." This radio was, for me, a symbol of Mary Ellen's and Walter's basic decency and solid values: no matter how many features the new radios have, you don't get rid of your old one if it's still working.

Mary Ellen was, of course, a woman mathematician at a time when there were few women mathematicians. She belonged, with Julia Robinson, Emma Lehmer and others, to what she called the housewives' generation: women who did substantial mathematics outside the academy, with only occasional ad hoc positions. I think of those women as exhibiting enormous strength of character. I think they thought of themselves as simply doing mathematics. As F. Burton Jones wrote in the Festschrift volume [J], "Wherever Mary Ellen was there was some mathematics." 
Feminist that I was, I would try to engage Mary Ellen about how the mathematical community treated women, with her as exhibit, if not A, then at least $\mathrm{E}$ or $\mathrm{F}$. She was not interested. "The best way to help women in mathematics is to do mathematics!" she roared at me, pounding the breakfast table at the 1974 Vancouver ICM. Yet she went out of her way to meet with young women and encourage them, and she told me many years after Vancouver that she had come to realize that when young she had protective blinders: she simply didn't notice the differences in how she was treated, so she wasn't hurt by them.

The last time I saw Mary Ellen was about a year after Walter died. By then she was using a walker and had moved into the guest bedroom off the living room to avoid the stairs. But she was still spending time every day thinking about mathematics simply because she loved it so much, working in Walter's old office on a huge table that I think was made out of a door plank. We went through the photos and reminiscences that people had sent her in homage to Walter, and her great no-nonsense good cheerfulness was still there, remembering all the times they had shared. There was a call about Bobby's care, and she excused herself to deal with it. She was going to meet with friends for lunch. Her life was full, her affect was vital, and I could not imagine that this would be the last time I would see her. But it was.

\section{Mirna Džamonja}

Much has already been said about Mary Ellen's outstanding personality and human quality. In this respect it is impossible for me to separate Mary Ellen from her alter ego and husband, Walter Rudin, as this is how I met them and perceived them one sunny day in the summer of 1986, when I was finishing the second year of my undergraduate degree at the University of Sarajevo in Yugoslavia (now Bosnia). They had come to see the university from which Amer Bešlagić, one of Mary Ellen's best students, had graduated; their visit was a major event in the mathematical life of the city. They each gave an excellent talk, and after Mary Ellen's talk, I knew I had found myself mathematically: the subject fascinated me, and the speaker perhaps even more so. I was invited to several social occasions with them then, and I was absolutely mesmerized by this couple, so different from each other, but so inseparable and complementary, the Old World and the New coming together in a unique mixture, which I had the honour to follow and know from that moment to the end of their lives. I could not have imagined then that we would become such close friends and that it is with Walter Rudin that I would dance at my wedding some years later

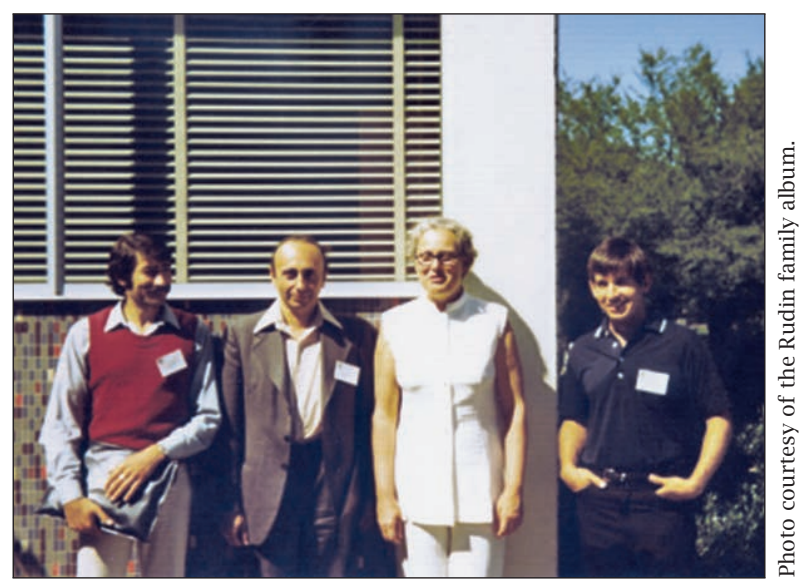

István Juhász, A. Hajnal, Mary Ellen, and Michael Starbird at the ICM in Vancouver in 1974.

and with Mary Ellen that I would discuss everything from mathematics to cooking. Mary Ellen was a brilliant mathematician, and even though it is hard to stop talking about her as a person, let me stop now and try to say something about her mathematical contribution. This is enormous and I have decided to concentrate on one aspect of it which I know the best, Dowker spaces.

The story of Dowker spaces starts with J. Dieudonné, who in his 1944 article [Di] considered sufficient conditions for a Hausdorff topological space $X$ to satisfy that for every pair $(h, g)$ of real functions on $X$ with $h<g$, if $h$ is upper semicontinuous and $g$ is lower semicontinuous, then there is a continuous $f: X \rightarrow \mathbb{R}$ such that $h<f<g$. C. H. Dowker in his 1951 article [Do] showed that this property is equivalent to the product $X \times[0,1]$ being normal (answering a conjecture of S. Eilenberg) and left open the possibility that this was simply equivalent to $X$ being normal. A possible counterexample, so a normal space $X$ for which $X \times[0,1]$ is not normal, became known as a Dowker space. In 1955, Mary Ellen Rudin [R55] showed that one can obtain a Dowker space from a Suslin line. At the time, the consistency of the existence or nonexistence of a Suslin line, of course, had not yet been known. M. E. Rudin returned to the problem in 1970 [R71b] when she gave an ingenious ZFC construction of a Dowker space as a subspace of the product $\prod_{n \geq 1}\left(\omega_{n}+1\right)$ in the box topology. This space has cardinality $2^{\mathrm{N}_{\omega}}$. This construction of Mary Ellen inspired a large amount of research, out of which I mention the two directions that are most interesting to me.

The first one is Z. Balogh's construction [B1] of a "small Dowker space," which was in this context taken to mean a Dowker space of cardinality $2^{\mathrm{N}_{0}}$ (which, of course, in some universes of set 


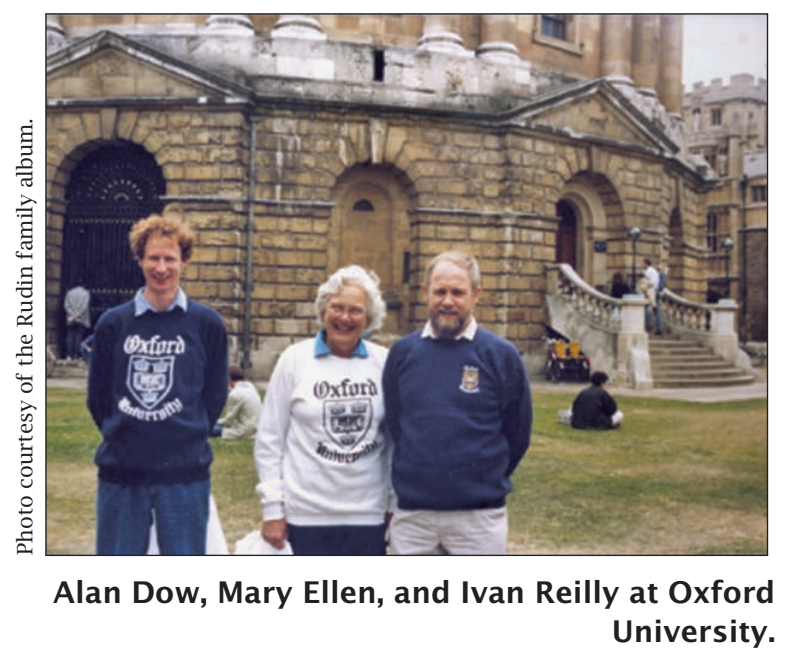

theory is as large as $2^{\mathrm{N}_{\omega}}$ but in others it is not). Balogh's method is a very intricate use of certain sequences of functions and elementary submodels, and reading it even today, one feels that its full limits have not yet been reached. The other direction was taken by M. Kojman and S. Shelah in [KS], where they used pcf theory to find a subspace of M. E. Rudin's space which is still Dowker, but has size $\kappa_{\omega+1}$. This construction rounds up the long list of set-theoretic techniques (forcing, large cardinals, pcf, ...) that were used in Mary Ellen's work and the work she inspired, carrying the field of general topology to what has since become known as set-theoretic topology. The interaction between set theory and set-theoretic topology has been most fruitful and has carried both subjects forward. Mary Ellen was the mother of it all. Let us hope that the unruly children that we are, we shall be able to carry forward not only Mary Ellen's mathematical legacy but also the legacy of the spirit of collaboration, inspiration, mutual respect and joy for all which she was able to create and live up to.

\section{Franklin Tall}

Set-theoretic topology was inspired by Mary Ellen Rudin for three decades. Her influence and leadership in North America and worldwide were central to the development of the field.

Mary Ellen grew up in a small town in Texas with no idea that she might become a mathematician. When R. L. Moore was trawling for prospects at registration at the University of Texas, he sensed she was a good one and began reeling her in. In classic Moore fashion, he created a confident, powerful researcher who didn't know

Franklin Tall is professor emeritus of mathematics at the University of Toronto, Toronto, Ontario, Canada. His email address is ta11@math.utoronto.ca. any mathematics other than what he led her to discover. Her thesis and first few papers are written in Moore's antiquated language, but Steve Watson $[W]$ has demonstrated that they are still well worth reading. In her thesis [R49], she gave the first example of a nonseparable Moore space satisfying the countable chain condition.

After positions at Duke (where she met her husband, Walter Rudin) and Rochester, the Rudins moved to the University of Wisconsin at Madison. The UW system had a nepotism regulation that prevented Mary Ellen from having a regular position because Walter had one. As a result, she stayed a "lecturer," which had one advantage: she was free of committee work. In 1971 the regulation was finally abolished, and she was promoted directly to full professor.

I first met Mary Ellen in the summer of 1967. I was casting around for a supervisor and Mary Ellen was very approachable, helpful, and encouragingqualities that supported a long line of students thereafter. I was her first PhD student, and in 1969 I had to have the department chair cosign my thesis because, as a lecturer, Mary Ellen was not allowed to be a full-fledged supervisor.

The first paper of Mary Ellen that most settheoretic topologists have heard of is [R55], in which she used a Suslin tree to construct a Dowker space. Such a construction would be quite interesting if done for the first time now, but in 1955 , before the consistency of the existence of such trees was known, this was quite extraordinary. She constructed a "real" Dowker space in [R71b], leading to an invitation to address the ICM.

The students of Moore such as Mary Ellen and R. H. Bing were familiar with both elementary set-theoretic techniques and geometric ones, especially dealing with connected spaces. Mary Ellen's geometric abilities proved invaluable in her work on pathological manifolds. Her most noteworthy result in this area is the consistency (with P. Zenor) and independence of the existence of perfectly normal nonmetrizable manifolds [R76], [R79].

Some other areas wherein she produced significant results are: classifying ultrafilters on the natural numbers (the Rudin-Keisler and RudinFrolik orders), showing (with Y. Benyamini and her student Mike Wage) that continuous images of Eberlein compacts (weakly compact subspaces of Banach spaces) are also Eberlein [BRW], and establishing many theorems about normality of products and box products. Let me give just one example of a normality theorem, consistently solving a problem of K. Morita. Mary Ellen, with her student Amer Bešlagić, proved in [BR]: Gödel's Axiom of Constructibility implies that for a space $X$ whose product with every metrizable space is normal, $X$ is metrizable if and only if $X \times Z$ is 
normal, for every space $Z$ such that $Z$ 's products with metrizable spaces are all normal. Amazingly, they proved this by constructing an example!

Mary Ellen's fame was largely as a producer of weird and wonderful topological spaces-examples and counterexamples. She had an uncanny ability to start off with a space that had some of the properties she wanted and then push it and pull it until she got exactly what she wanted. In her heyday, several times a week she would receive inquiries from mathematicians around the worldoften nontopologists-asking for an example of something or other. She would answer these by writing back on the back of the same letter, not from "green" sentiments, but to avoid clutter. I am convinced that her avoidance of clutter, especially mentally, was one of the secrets of her mathematical power. By not filling up her memory, she maximized processing capability in her brain.

Mary Ellen's papers became (and stayed) more set-theoretic, starting in the late 1960s. There were a variety of reasons for this in addition to what Marxists might call "historical necessity." The most important reason was that set theory was being done at Wisconsin, most notably by Ken Kunen, who arrived in 1968. David Booth and I were both students in logic who had begun thinking about applications of set theory to topology; we frequently went back and forth between Ken and Mary Ellen, and that accelerated the collaboration that made Madison such an exciting place for set-theoretic topology in the 1970s. During the summers I and many other set-theoretic topologists would come to visit and interact with Mary Ellen and Ken. The most memorable summer, though, was the one of 1974, when we all went off to the CBMS Regional Conference in Laramie, Wyoming, for Mary Ellen's lectures on set-theoretic topology [R75]. I remember the sense of excitement we felt at Mary Ellen's lectures, which set the course of the field for the next decade. The resulting book, with chapters on cardinal functions, hereditary separability versus hereditary Lindelöfness, box products, and so forth, established a framework for the new field of set-theoretic topology, which grew out of general topology but employed new methods, which led to new questions. It was an exciting time. It was a noteworthy challenge to try to solve a problem on her problem list.

We celebrated Mary Ellen in 1991 on the occasion of her retirement with a conference in Madison. The proceedings were published in [T1]; much of this note is drawn from my contribution [T2] in [T1], where more details of her mathematics can be found. There is also the excellent biographical article [AR]. Mary Ellen's research certainly did not stop with her retirement. Particularly impressive was her complex proof of Nikiel's Conjecture,

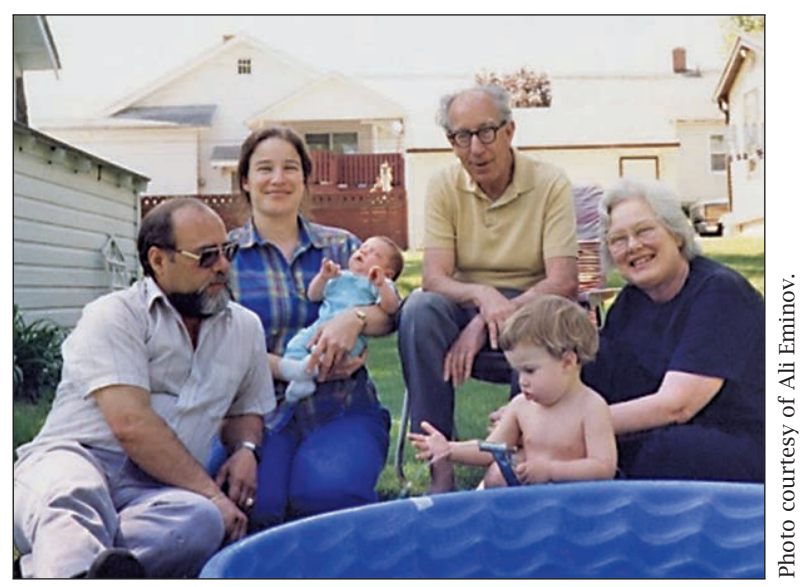

Mary Ellen and Walter with daughter Catherine's family: Ali Eminov, Catherine, and their sons, Deniz and Adem Rudin.

characterizing the continuous images of compact ordered spaces as the compact monotonically normal spaces [R01]. As Steve Watson wrote in [W] (quoted by Todd Eisworth in his review [E] of [R01]), "Reading the articles of Mary Ellen Rudin, studying them until there is no mystery takes hours and hours; but those hours are rewarded, the student obtains power to which few have access. They are not hard to read, they are just hard mathematics, that's all."

Although her body failed her, her mind remained sharp as she aged. She stopped traveling, and I was busy with family responsibilities, so I saw little of her in recent years, but she remained and remains an inspiration for all of us in the field.

\section{Peter Nyikos}

I had the honor of delivering a short eulogy for Mary Ellen at this year's Spring Topology and Dynamics Conferences (STDC) in Connecticut. It said: "Mary Ellen was a great mathematician. But she was much more than that: she was what Prabir Roy called a guru-someone you could turn to for advice and comfort on all kinds of matters...To those of us who knew her well, she was simply 'Mary Ellen.' Whenever set-theoretic topologists got together for a chat, and someone said 'Mary Ellen,' 99 times out of a hundred, everyone would know who was being talked about."

I briefly listed some of her main accomplishments, including of course the writing of "Mary Ellen's booklet" [R75], another expression that usually gets instant recognition. Among her research accomplishments is a beautiful generalization of

Peter Nyikos is professor of mathematics at the University of South Carolina. His email address is nyi kos@math. sc . edu. 


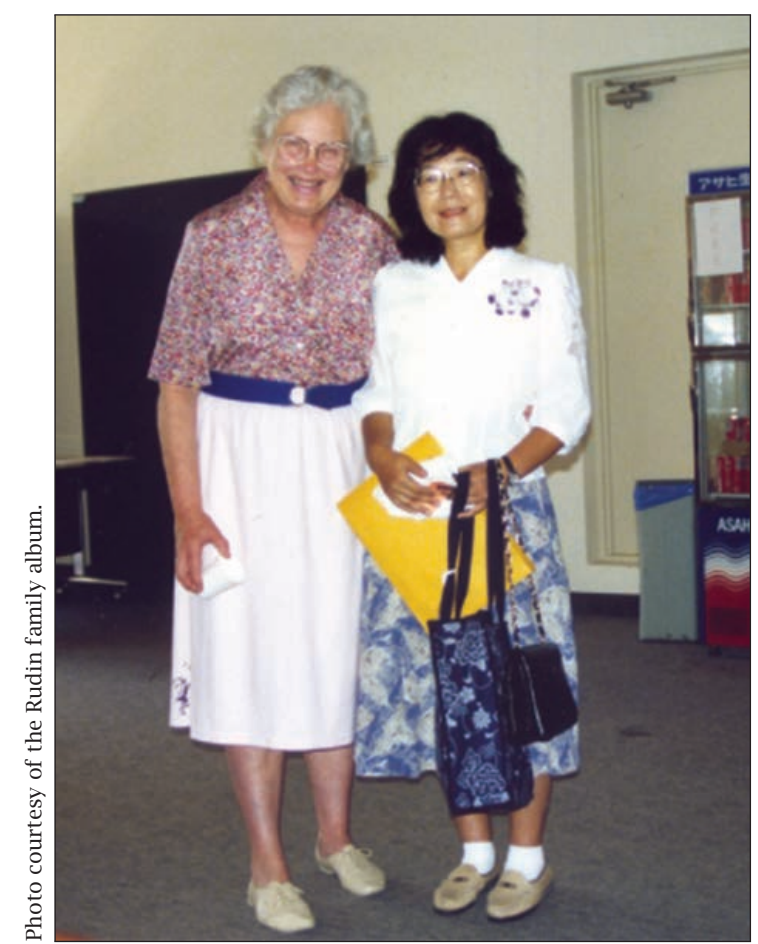

Mary Ellen and and co-author Keiko Chiba in Kyoto for the ICM in 1990.

the Hahn-Mazurkiewicz theorem. It is an immediate corollary of her solution to Nikiel's Conjecture [R01] and of a 1988 theorem of Nikiel [Ni]. The HahnMazurkiewicz theorem states that, if a metrizable space is a locally connected continuum (compact, connected space), then it is a continuous image of $[0,1]$. (The converse is elementary.) These spaces are called "Peano continua" in recognition of Peano's space-filling curve. Back in 1966 [M], Sibe Mardešić wrote: "It is natural to ask for a nonmetric analogue of this theorem.... Recently the interest in this and related problems has been revived...." Mary Ellen's solution to Nikiel's Conjecture allows one to substitute "monotonically normal" for "metrizable" in the Hahn-Mazurkiewicz theorem. And the proof that every metric space is monotonically normal is essentially identical to the usual proof that every metric space is normal. The search for a natural extension of the Hahn-Mazurkiewicz theorem to compact connected, linearly ordered spaces was akin to the search for a metrization theorem generalizing the Urysohn metrization theorem, and it lasted even longer. (The Bing-Nagata-Smirnov theorem was hailed as the solution to this metrization problem after a search of over three decades.)

I closed my eulogy by expressing the hope that there would be some publications in remembrance of Mary Ellen that would do justice to her greatness, and I am very happy to be able to contribute both to the special issue of Topology and its Applications dedicated to Mary Ellen and to this remembrance.

I got a unique taste of Mary Ellen's graciousness and hospitality in early 1974, when I was a postdoctoral student at the University of Chicago. She invited me up to Madison, where I arrived with a bad cold (I naïvely decided not to postpone the visit, which had already been delayed a number of times), but although it was obvious to everyone, she never mentioned it once and had me stay overnight at her house, where I met her two sons and played board games with them. The same evening she introduced me to the axioms $\diamond$ and * and to Ostaszewski's $S$-space, all of which were totally new to me at the time.

The next two years I saw her at the two STDC conferences, where I became impressed first by her lecturing style and then by the high regard in which she was held. There was a panel discussion in Memphis about the future of point-set topology, and the panel included Mary Ellen and other leading figures such as R. H. Bing, R. D. Anderson, A. H. Stone, and E. Michael.

Her paper on her screenable Dowker space [R83] solved a 1955 problem of Nagami whether every normal, screenable space is paracompact [Na]. The proof of normality was a tour de force, amazing in its originality. I had never seen anything remotely like it, nor the way she was able to use the intricate set-theoretic axiom $\diamond^{++}$to define the space itself. To this day I have no idea how it entered into her mind that a peculiar space like this would have all the properties required to solve Nagami's problem nor how she was able to decide on the way to use $\diamond^{++}$in the definition. One part of her paper reminded me of an anecdote that was told about a session in the Laramie workshop. She had been going over a particularly intricate construction when F. Burton Jones interrupted: "What allows you to say that?" Mary Ellen replied, "Why that's-that's just God-given." "Yes," Jones is supposed to have said, "but what did God say when he gave it to you?"

There were some problems in set-theoretic topology which Mary Ellen could not solve but on which she did obtain large "consolation prizes." One such prize was her screenable Dowker space, an offshoot of her unsuccessful attempts to solve a problem for which we still have no consistency results: is there a normal space with a $\sigma$-disjoint base that is not paracompact? Zoltán Balogh later [B2] came up with one of his "greatest hits": a ZFC example of a screenable Dowker space. Mary Ellen's consistent example is, however, the only one known to be collectionwise normal. A recurring theme in Mary Ellen's research, up to the very end of her life, were two further problems about Dowker spaces: the problem of whether there is a 


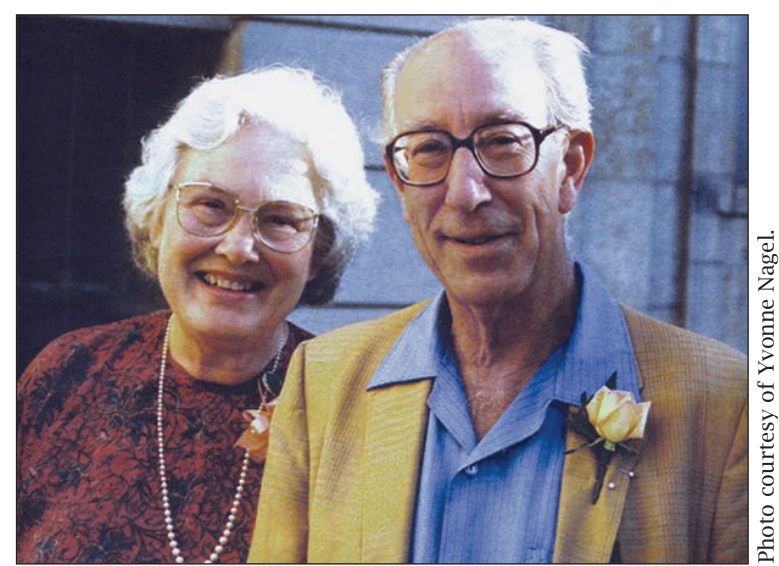

Mary Ellen and Walter when they retired in 1991.

normal, linearly Lindelöf space that is not Lindelöf and the problem of whether there is a normal space with a $\sigma$-disjoint base that is not paracompact.

\section{Kenneth Kunen and Arnold Miller}

There is an excellent biographical interview of Mary Ellen published in [AR]. Also, there is an entire volume [T1] devoted to articles describing her mathematics. All quotations below are taken from [T1].

Mary Ellen Rudin was one of the leading topologists of our time. Besides solving a number of well-known outstanding open problems, she was a pioneer in the use of set-theoretic tools. She was one of the first to apply the independence methods of Cohen and others to produce independence results in topology. She did not do forcing arguments herself, but many of her papers make use of set-theoretic statements, such as Martin's Axiom, Suslin's Hypothesis, and $\diamond$, that other researchers have shown to be true in some models of set theory and not in others.

In her thesis [R49] she gave an example of a nonseparable Moore space that satisfies the countable chain condition. She published the results of her thesis in three papers in the Duke Math Journal [R50], [R51], [R52].

To quote Steve Watson, "This cycle represents one of the greatest accomplishments in set-theoretic topology. However the mathematics in these papers is of such depth that, even forty

Kenneth Kunen is professor emeritus of mathematics at the University of Wisconsin at Madison. His email address is kunen@math.wisc.edu.

Arnold Miller is professor of mathematics at the University of Wisconsin-Madison. His email address is mi11er@ math.wisc.edu. years later, they remain impenetrable to all but the most diligent and patient of readers."

In [R55] she used a Suslin tree to construct a Dowker space. The existence of a Suslin tree is consistent with ZFC but not provable from ZFC. In [R71a, R71b] she constructed a Dowker space just in ZFC. This space has cardinality $\left(\aleph_{\omega}\right)^{\mathrm{N}_{0}}$, whereas the Suslin tree yields a Dowker space of size only $\mathrm{N}_{1}$. Also, in 1976 [JKR] she showed that $\mathrm{CH}$ yields a Dowker space of size $\kappa_{1}$. It is still an open question whether one can prove in ZFC that there is a Dowker space of size $\kappa_{1}$. There is one of size $\kappa_{\omega+1}$ by Kojman and Shelah [KS].

Her work on Dowker spaces led to an invited address at the International Congress of Mathematicians in 1974. It also led to her interest in the box topology, because her Dowker space of size $\left(\aleph_{\omega}\right)^{\aleph_{0}}$ is a special kind of box product.

Mary Ellen is famous for her work on box products. If $X_{n}$ (for $n \in \omega$ ) are topological spaces, then $\square_{n} X_{n}$ denotes the product of the spaces $\prod_{n} X_{n}$ using the box topology; a base for this topology is given by all sets $\prod_{n} U_{n}$, where each $U_{n}$ is open in $X_{n}$. The more well-known Tychonov topology, used to prove the Tychonov Theorem (1935), requires that $U_{n}=X_{n}$ for all but finitely many $n$. Mary Ellen was the first person to prove anything nontrivial about box products. In [R72b] she showed that, assuming $\mathrm{CH}, \square_{n} X_{n}$ is normal, and in fact paracompact, whenever all the $X_{n}$ are compact metric spaces. Also, her 1974 paper [R74] shows that $\square_{n} X_{n}$ is paracompact whenever all the $X_{n}$ are successor ordinals; this easily generalizes to the case where the $X_{n}$ are compact scattered spaces (see $[\mathrm{Ku}]$ ). It was later shown by Eric van Douwen, in ZFC, that there are always compact Hausdorff $X_{n}$ for which $\square_{n} X_{n}$ is not normal. The question of which of Mary Ellen's positive results can be proved in ZFC remains an outstanding unsolved problem in topology. Even the case where

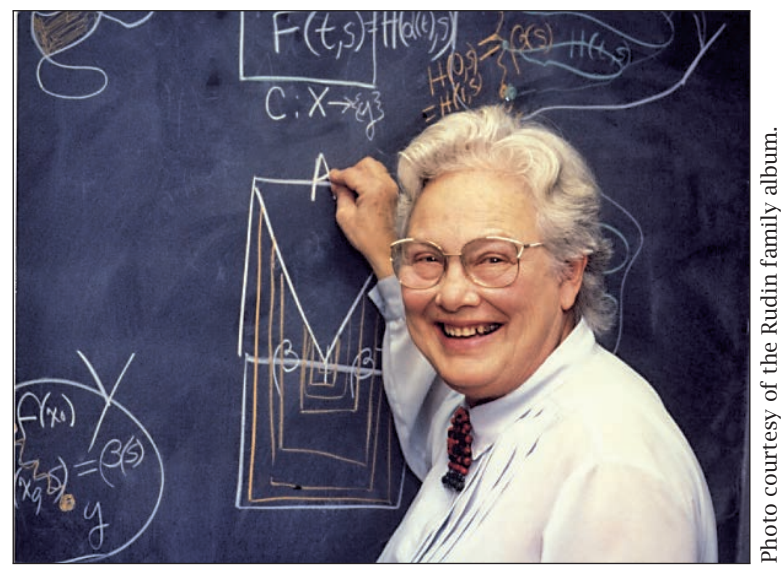

Mary Ellen lecturing. 


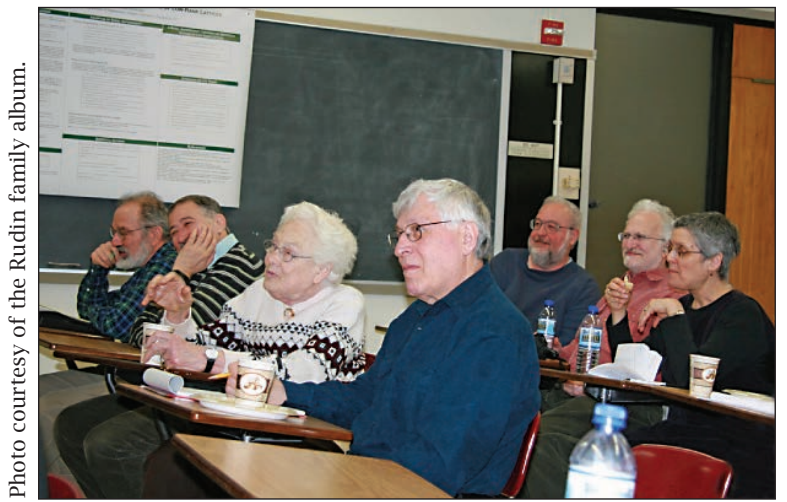

At the Kunen Fest 2009: (left to right/front row, back row) Ken Kunen, István Juhász, Mary Ellen, Jerry Keisler, Arnold Miller, Franklin Tall, Judy Roitman.

all $X_{n}=\omega+1$ remains open, although this case (or when all $X_{n}$ are compact metric) does follow from Martin's Axiom.

Mary Ellen is also famous for her work on $\beta \mathbb{N}$, the space of ultrafilters on the natural numbers, starting in 1966. She was coinventor of two well-known partial orders on this space: the RudinKeisler order and the Rudin-Frolik order. The basic properties of these are given in her 1971 paper [R71c], although their historic roots go back somewhat earlier.

The Rudin-Frolik order led to the first proof in ZFC that the space of nonprincipal ultrafilters, $\mathbb{N}^{*}=\beta \mathbb{N} \backslash \mathbb{N}$, is not homogeneous. Under $\mathrm{CH}$ this was already known by a result of Walter Rudin (1956), who proved from $\mathrm{CH}$ that there is a P-point $\mathcal{U} \in \mathbb{N}^{*}$ (that is, $\mathcal{U}$ is in the interior of every $G_{\delta}$ set containing $\mathcal{U}$ ). Nonhomogeneity follows because every infinite compactum also has a non-P-point $\mathcal{V}$, and no homeomorphism of $\mathbb{N}^{*}$ can move this $\mathcal{V}$ to Walter's $\mathcal{U}$. It was shown much later (Shelah, in the 1970s) that one cannot prove in ZFC that these P-points exist.

For the Rudin-Frolik order, for $\mathcal{U}, \mathcal{V} \in \mathbb{N}^{*}$, say that $\mathcal{U}<_{\mathrm{RF}} \mathcal{V}$ iff $\mathcal{V}$ is a $\mathcal{U}$-limit of some discrete $\omega$-sequence of points in $\mathbb{N}^{*}$. One can show that this is a partial order; also, if $\mathcal{U}<_{\mathrm{RF}} \mathcal{V}$, then no homeomorphism of $\mathbb{N}^{*}$ can move $\mathcal{V}$ to $\mathcal{U}$, proving nonhomogeneity.

The Rudin-Keisler order comes naturally out of the notion of induced measure. If $\mathcal{U}, \mathcal{V}$ are ultrafilters on any set $I$, we say that $\mathcal{U} \leq_{\mathrm{RK}} \mathcal{V}$ iff there is a map $f: I \rightarrow I$ that induces the measure $\mathcal{U}$ from $\mathcal{V}$; that is, $\mathcal{U}=\left\{X \subseteq I: f^{-1}(X) \in \mathcal{V}\right\}$. When $\mathcal{U}, \mathcal{V} \in \mathbb{N}^{*}, \mathcal{U}<_{\mathrm{RF}} \mathcal{V}$ implies that $\mathcal{U} \leq_{\mathrm{RK}} \mathcal{V}$ and $\mathcal{V} \varliminf_{\mathrm{RK}} \mathcal{U}$. This order is of importance in model theory, in the theory of ultraproducts, since $\mathcal{U} \leq_{\mathrm{RK}} \mathcal{V}$ yields a natural elementary embedding from $\prod_{i} \mathfrak{A}_{i} / \mathcal{U}$ into $\prod_{i} \mathfrak{A}_{i} / \mathcal{V}$. It is also important in the combinatorics of ultrafilters, since the RudinKeisler minimal elements of $\mathbb{N}^{*}$ are precisely the Ramsey ultrafilters; such minimal elements exist under $\mathrm{CH}$ but not in ZFC. It is true, but not completely trivial, that neither of these two orders is a total order; that is, in ZFC there are $\mathcal{U}, \mathcal{V} \in \mathbb{N}^{*}$ such that $\mathcal{U}{\varliminf_{\mathrm{RK}}} \mathcal{V}$ and $\mathcal{V}{\varliminf_{\mathrm{RK}}} \mathcal{U}$ (and hence also $\mathcal{U} k_{\mathrm{RF}} \mathcal{V}$ and $\mathcal{V} k_{\mathrm{RF}} \mathcal{U}$ ). The paper [RS] (1979) of Mary Ellen and Saharon Shelah gives the strongest possible result: for each infinite $\kappa$, there is a family of $2^{2^{\kappa}}$ ultrafilters on $\kappa$ that are pairwise incomparable in the Rudin-Keisler ordering. Mary Ellen worked extensively on the question of $S$ - and $L$-spaces. She produced the first $S$-space (a hereditarily separable space that is not hereditarily Lindelöf) assuming the existence of a Suslin tree in 1972 [R72a]. Her Dowker space constructed from $\mathrm{CH}$ (see above) is also an $S$ space. Her 1975 monograph [R75] devotes an entire chapter to $S$ - and $L$-spaces. To quote Stevo Todorčević, "The terms ' $S$-space' and ' $L$-space,' which are predominant in most of the literature on this subject, are also first found in these lectures. This shows a great influence not only of [R75] but also of M. E. Rudin's personality on the generation of mathematicians working in this area, since it is rather unusual in mathematics to talk about certain statements in terms of their counterexamples."

In 1999, almost a decade after her retirement, Mary Ellen settled a long-standing conjecture in set-theoretic topology by showing that every monotonically normal compact space is the continuous image of a linearly ordered compact space. This paper [R01] was the final one in a series of five which gradually settled more and more special cases of the final result. The construction of the linearly ordered compact space is extraordinarily complex, and to this date there is no simpler proof known.

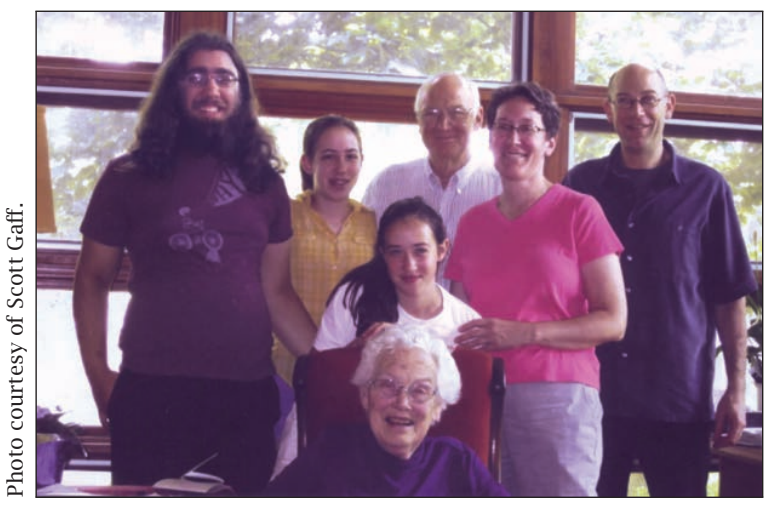

At the time of Walter's memorial gathering in 2010: Mary Ellen with grandson Deniz, granddaughter Sofie, brother Joe Estill, daughter Eleanor, son Charlie, and granddaughter Natalie. 
Mary Ellen was by consensus a dominant figure in general topology. Her results are difficult, deep, original, and important. The connections she found between topology and logic attracted many set-theorists and logicians to topology. The best general topologists and set-theorists in the world passed regularly through Madison to visit her and work with her and her students and colleagues.

She had eighteen PhD students, many of whom went on to have sterling careers of their own. To quote one of them, Michael Starbird, "From the perspective of a graduate student and collaborator, her most remarkable feature is the flood of ideas that is constantly bursting from her.... It is easy to use the Mary Ellen Rudin model to become a great advisor. The first step is to have an endless number of great ideas. Then merely give them totally generously to your students to develop and learn from. It is really quite simple. For Mary Ellen Rudin.”

\section{References}

[AR] D. J. Albers and C. ReID, An interview with Mary Ellen Rudin, College Math. J. 19:2 (1988), 114-137. www.jstor.org/stable/pdfplus/2686174.pdf.

[B1] Z. T. BALOGH, A small Dowker space in ZFC, Proc. Amer. Math. Soc. 124 (1996), no. 8, 2555-2560.

[B2] A normal screenable nonparacompact space in ZFC, Proc. Amer. Math. Soc. 126 (1998), no. 6, 18351844.

[BR] A. BEŠLAGIĆ and M. E. RUDIN, Set-theoretic constructions of nonshrinking open covers, Topology Appl. 20 (1985), no. 2, 167-177.

[BRW] Y. BENYAMINI, M. E. Rudin, and M. WAGe, Continuous images of weakly compact subspaces of Banach spaces, Pacific J. Math. 70 (1977), 309-324.

[Di] J. Dieudonné, Une généralisation des espaces compacts, J. Math. Pures Appl. (9) 23 (1944), 65-76.

[Do] C. H. Dowker, On countably paracompact spaces, Canadian J. Math. 3 (1951), 219-224.

[E] E. T. EISWORTH, Review of Rudin, Mary Ellen, Nikiel's conjecture, Topology Appl. 116 (2001), no. 3, 305331. MR1857669

[J] F. B. JonEs, Some glimpses of the early years, The Work of Mary Ellen Rudin, ed. Franklin D. Tall, Annals of the New York Academy of Sciences, 705, 1993, pp. xi-xii.

[JKR] I. Juhász, K. Kunen, and M. E. Rudin, Two more hereditarily separable non-Lindelöf spaces. Canad. J. Math. 28 (1976), 998-1005.

[Ke] P. Kenschaft, Change Is Possible: Stories of Women and Minorities in Mathematics, Amer. Math. Soc., Providence, RI, 2005.

[KS] M. KoJMAn and S. ShelaH, A ZFC Dowker space in $\aleph_{\omega+1}$ : an application of PCF theory to topology, Proc. Amer. Math. Soc. 126 (1998), no. 8, 2459-2465.

[Ku] K. KunEN, Paracompactness of box products of compact spaces, Trans. Amer. Math. Soc. 240 (1978), 307-316.

[M] S. MARDEŠIĆ, On the Hahn-Mazurkiewicz problem in nonmetric spaces, General Topology and Its Relations to Modern Analysis and Algebra II: Proceedings of the Second Prague Topological Symposium, 1966, J. Novák, ed., Academic Press, 1967, pp. 248-255.

[Na] K. NAGAMI, Paracompactness and strong screenability, Nagoya Math. J. 8 (1955), 83-88.

[Ni] J. NiKIEL, Images of arcs - a nonseparable version of the Hahn-Mazurkiewicz theorem, Fund. Math. 129 (1988), no. 2, 91-120.

[R49] M. E. EsTILL, Concerning Abstract Spaces, PhD Thesis, The University of Texas at Austin, 1949.

[R50] M. E. RuDIN, Concerning abstract spaces, Duke Math. J. 17 (1950), 317-327.

[R51] _ Separation in non-separable spaces, Duke Math. J. 18 (1951), 623-629.

[R52] _ Concerning a problem of Souslin's, Duke Math. J. 19 (1952), 629-639.

[R55] _ Countable paracompactness and Souslin's problem, Canad. J. Math. 7 (1955), 543-547.

[R71a] _ A normal space $X$ for which $X \times I$ is not normal, Bull. Amer. Math. Soc. 77 (1971), 246.

[R71b] , A normal space $X$ for which $X \times I$ is not normal, Fund. Math. 73 (1971/72), 179-186.

[R71c] , Partial orders on the types in $\beta \mathbb{N}$, Trans. Amer. Math. Soc. 155 (1971), 353-362.

[R72a]_, A normal hereditarily separable nonLindelöf space, Illinois J. Math. 16 (1972), 621626.

[R72b] _ The box product of countably many compact metric spaces, General Topology Appl. 2 (1972), 293-298.

[R74] _ Countable box products of ordinals, Trans. Amer. Math. Soc. 192 (1974), 121-128.

[R75] _ Lectures on Set Theoretic Topology, Expository lectures from the CBMS Regional Conference held at the University of Wyoming, Laramie, Wyo., August 12-16, 1974. Conference Board of the Mathematical Sciences Regional Conference Series in Mathematics, No. 23, Amer. Math. Soc., Providence, RI, 1975.

[R76] M. E. RUDIN and P. ZENOR, A perfectly normal nonmetrizable manifold, Houston J. Math. 2 (1976), no. 1, 129-134.

[R79] M. E. RUDIN, The undecidability of the existence of a perfectly normal nonmetrizable manifold, Houston $J$. Math. 5 (1979), no. 2, 249-252.

[R83] _ A normal, screenable, nonparacompact space, Topology Appl. 15 (1983), no. 3, 313-322.

[R01] _ Nikiel's conjecture, Topology Appl. 116 (2001), no. 3, 305-331.

[RS] M. E. RUDIN and S. SHELAH, Unordered types of ultrafilters, Proceedings of the 1978 Topology Conference (Univ. Oklahoma, Norman, Okla., 1978), I. Topology Proc. 3 (1978), no. 1, 199-204 (1979).

[RW] W. RuDIN, The Way I Remember It, History of Mathematics 12, Amer. Math. Soc., Providence, RI; London Math. Soc., London, 1997.

[T1] F. D. TALL, editor, The Work of Mary Ellen Rudin, Papers from the Summer Conference on General Topology and Applications in Honor of Mary Ellen Rudin Held in Madison, Wisconsin, June 26-29, 1991, Annals of the New York Academy of Sciences, 705, New York Academy of Sciences, New York, 1993.

[T2] IBID., pp. 1-16.

[W] S. WATSON, Mary Ellen Rudin's early work on Suslin spaces, The Work of Mary Ellen Rudin, F. D. Tall, ed., Annals of the New York Academy of Sciences, 705, 1993, pp. 168-182. 